\title{
DISCUSSION
}

\section{Seismic precursor to instability induced by internal erosion in loose granular slopes}

\author{
WEI HU*, PIERRE-YVES HICHER $\uparrow$, GIANVITO SCARINGI†, QIANG XU*, THEO W. J. VAN ASCH*§, \\ GONGHUI WANG\|, WEI CHAO LIף, GANG DENG $\|$ and XIANG QIAN LIANG
}

\section{Contribution by Wei Chao Li et al.}

The discussers thank the authors for their effort in investigating the precursor to instability induced by internal erosion in loose, granular slopes (Hu et al., 2018a). In the discussed paper, the internal erosion was observed in flume experiments and the contribution of internal erosion to instability was investigated through undrained triaxial tests. However, the internal stability of materials collected from the loose deposit of the rock avalanche in the Wenjia gully and used for the flume experiments requires further discussion.

In the discussed paper, the grading of the materials collected from the loose deposit of the rock avalanche in the Wenjia gully and grading used for the flume tests were presented in Fig. 3. The potential for internal instability as a result of seepage is usually evaluated based on the slope of the grain-size distribution curve. The two commonly used criteria were suggested by Kezdi (1979) and Kenney \& Lau $(1985,1986)$. For the Kezdi criteria for instability, 'the slope is flatter than 15\% per four times change in grain size' ( $\mathrm{Li} \&$ Fannin, 2008: p. 1303), namely $H=15 \%$. For the Kenney and Lau criteria for instability, 'the slope is flatter than $F \%$ per four times change in grain size' (Li \& Fannin, 2008: p. 1303), namely $H=1 \cdot 0 F$, where $H$ is the percentage of mass increment and $F$ is the percentage of mass passing. Li \& Fannin (2008) synthesised the two criteria and carried out comparative analysis to account for relative conservatism.

Figure 19 presents the evaluation of the internal instability of the grain-size distribution curve collected from the site and used for flume experiments based on the comparative framework suggested by $\mathrm{Li} \&$ Fannin (2008). It shows that the grading collected from the site locates completely out of the unstable zone; part of the grading used for the flume experiments is located at the margin of the unstable zone, but the particle size finer than $1 \mathrm{~mm}$, which is lost in the flume experiments, locates completely out of the unstable zone.

The material in the discussed paper is internally stable according to the evaluation based on the grain-size

\footnotetext{
* State Key Laboratory of Geo-Hazard Prevention and GeoEnvironment Protection, Chengdu University of Technology, Chengdu, P. R. China.

$\dagger$ Ecole Centrale de Nantes, Nantes, France.

* Institute of Hydrogeology, Engineering Geology and Applied Geophysics, Faculty of Science, Charles University, Prague, Czech Republic.

$\S$ Faculty of Geosciences, Utrecht University, Utrecht, the Netherlands.

|| Disaster Prevention Research Institute, Kyoto University, Kyoto, Japan.

I State Key Laboratory of Simulation and Regulation of Water Cycle in River Basin, Beijing, P. R. China; Department of Geotechnical Engineering, China Institute of Water Resources and Hydropower Research, Beijing, P. R. China.
}

distribution curve, but internal erosion was observed in the flume experiments. The discrepancy needs to be clarified.

In the discussed paper, 'the flume floors are covered by calcareous grains glued to a rubber sheet in order to reproduce an impervious frictional contact' ( $\mathrm{Hu}$ et al., 2018a: p. 990); the size of the calcareous grains was not provided. The calcareous grains are under and in contact with the material used for the flume experiments, hence it is necessary to clarify whether contact erosion will occur or not.

\section{Authors' reply (Wei Hu and Gianvito Scaringi)}

The authors are grateful to the discussers for the interest shown in their work.

Kenney \& Lau (1985) provided an empirical criterion for instability based on experiences relating to dense soils. Accordingly, the slope of the secant of the grain-size distribution curve of a stable soil in the $F(d)-d$ plane (where $F(d)$ is the passing fraction in mass, expressed as a percentage, at a given grain size $d$ ), calculated at any $d \leq d_{20}$ over a fourfold increment of grain size (i.e. from $d$ to $4 d$ ), should be larger than 1.66 times $F(d)$ (Chapuis, 1992). In other words, the criterion suggests that dense soils can express instability only if their grain-size distribution curve, in the domain of the relatively small particles $\left(d \leq D_{20}\right)$, maintains a very gentle, $d$-dependent slope: at most 0.333 at $d=D_{20}, 0 \cdot 167$ at $d=D_{10}, 0.083$ at $d=D_{5}$ and so on. Such a criterion is, evidently, quite restrictive, yet it might be reasonable, indeed, for dense soils, in which the size of the pores can be much smaller than that in loose soils with the same grain-size distribution. Smaller pores imply that only a small fraction of the soil, with size much smaller than that of the particles constituting the stress-bearing skeleton, can be effectively transported through the pore network. On the other hand, it seems reasonable that a less restrictive condition on the slope of the grain-size distribution curve should apply to loose, granular assemblies, such as the soil utilised in flume experiments by the authors (Hu et al., 2017, 2018a, 2018b, 2018c). In fact, by utilising the same granular assembly, which was prepared at different initial relative densities (RD), the authors (Hu et al., 2018c) also demonstrated the strong control of the latter on the occurrence of internal erosion, micro-seismicity, acoustic emissions and macroscopic instability with consequent fluidisation of the soil mass. In slopes with $\mathrm{RD} \leq 0 \cdot 45$, failure with fluidisation occurred; at $\mathrm{RD}=0.69$, progressive failure occurred, but without fluidisation. Finally, at $\mathrm{RD}=0.81$ and $\mathrm{RD}=0.95$, the slopes remained stable under hydrological forcing for a long time, and did not produce significant seismic or acoustic signals; this was actually consistent with what was expected from Kenney \& Lau's (1985) criterion, as observed by the discussers. The authors, therefore, believe that the criterion proposed by Kenney \& Lau (1985), subsequently incorporated by the 


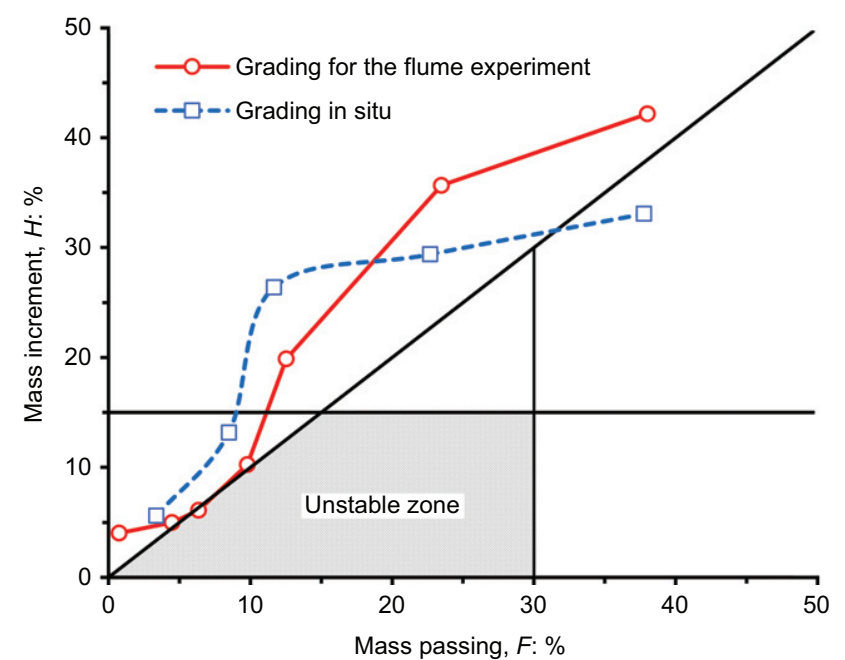

Fig. 19. Evaluation of the internal stability of grading in situ and for the flume experiment

discusser in a bilinear criterion, could lead to unconservative assessments if applied to soils with any RD - that is, a soil could be assessed as stable whereas, in fact, it can be unstable if it occurs at low RD.

The method proposed by Kezdi (1979), as observed by Chapuis (1992), is equivalent in principle to that of Sherard (1979). The two methods can thus be examined together, as they only disagree on the threshold value of the instability ratio, $I_{\mathrm{r}}(d)$, above which instability can occur. The value of $I_{\mathrm{r}}$ is calculated, after subdividing the soil into a coarser and a finer fraction with $d$ as a threshold, as the ratio of $D_{15}$ of the coarser fraction to $D_{85}$ of the finer fraction. While Kezdi (1979) considers unstable those soils for which $I_{\mathrm{r}}>4$ for some values of $d$, Sherard (1979) fixes the threshold value at 5 . By means of a simple geometrical exercise, considering a soil composed of grains of only two sizes in appropriate proportions, Kezdi (1979) provides a physical justification for these values by deriving $I_{\mathrm{r}}>1+2 \sqrt{3} \cong 4.5$ for the densest possible state, and $I_{\mathrm{r}}>1+\sqrt{2} \cong 2.4$ for the loosest possible state. Kezdi suggests that values of 4-5 should be used, as natural assemblies are generally characterised by a continuous distribution of grain sizes. It is worth noting, however, that Kezdi (1979), similarly to Kenney \& Lau (1985), discussed soil instability having in mind the internal erosion in embankment dams, where the material is not supposed to exist in a loose state.

By plotting the instability ratio against the grain size, interesting observations can be made (Fig. 20). While the criterion for loose assemblies of grains of only two sizes $\left(I_{\mathrm{r}}>2 \cdot 4\right)$ might appear overly conservative, the criteria of Kezdi (1979) and Sherard (1979) suggest that particles of size $d<0 \cdot 3-0.4 \mathrm{~mm}$ should be unstable in the flume assembly (i.e. they might be internally eroded and transported by seepage), and similarly that particles of size $d<1.9-2.2 \mathrm{~mm}$ should be unstable in the actual soil deposit. It is possible that these threshold values of $d$ are somewhat of an underestimation if one recalls that loose soils should have lower thresholds for $I_{\mathrm{r}}$ than the dense soils for which these thresholds were devised (see above). Nonetheless, the similarity of the threshold values for $d$ in the flume tests and in situ with those actually observed is striking: see, in this respect, Fig. 7(c) in the paper by $\mathrm{Hu}$ et al. (2018a) and Fig. 4(i) in the paper by $\mathrm{Hu}$ et al. (2018b) for the fraction eroded in the flume tests, and refer to Zhang et al. (2014), Li et al. (2016) and Wang et al. (2017) for in situ observations. It can also be seen in Fig. 20 that the soil tested in the flume

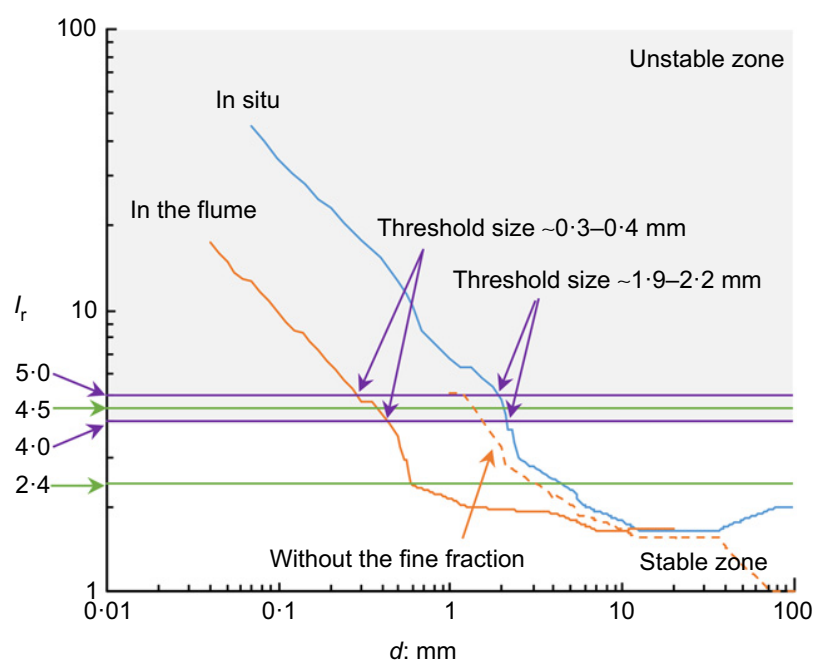

Fig. 20. Instability ratio $\left(I_{\mathrm{r}}\right)$ plotted against the grain size $(d)$ for the material in situ, and for the granular assembly utilised in the flume tests with (unstable) or without (stable) the fine fraction. The $I_{\mathrm{r}}(d)$ values are compared with various instability criteria: $I_{r}>4$ (Kezdi, 1979); $I_{r}>5$ (Sherard, 1979); soils with grains of only two sizes in the densest state $\left(I_{r}>4 \cdot 5\right)$ and in the loosest state $\left(I_{r}>2 \cdot 4\right)$

without the fraction $d<1 \mathrm{~mm}$ is indeed stable according to the considered criteria. A soil that is initially potentially unstable, but undergoes coarsening and densification by progressive removal of its finest fraction by internal erosion induced by seepage, with gradients insufficient to cause macroscopic instability, might eventually become stable and remain in place even under a hydrological forcing stronger than that which, in the original condition, would have caused failure and fluidisation. This has been discussed by the authors ( $\mathrm{Hu}$ et al., 2018b), and proposed as a possible physical mechanism responsible for the healing-in-place of loose, granular deposits deriving from coseismic landslides (cf. field data and discussions by Fan et al. (2018, 2019)). By means of numerical experiments, moreover, the increased hydraulic conductivity (cf. Hu et al., 2017, 2018a, 2018c) of the coarsened deposits has been found capable of justifying a strong decrease in runoff-induced debris flow activity in a catchment rich with loose, granular deposits and, at the same time, an increase of the hydrological threshold required to trigger instabilities (Domènech et al., 2019), which is consistent with field observations (Fan et al., 2018, 2019).

Finally, regarding the concern of the discussers about the effectiveness of the rough bottom surface of the flume in preventing basal sliding, the authors wish to specify that sand and gravel grains with size up to $1 \mathrm{~cm}$ were glued to the bottom surface to this purpose. Moreover, it can be understood clearly from the particle image velocimetry study (Fig. 10 in $\mathrm{Hu}$ et al. (2018a)) that the instability occurs along a curvilinear surface which is internal to the granular mass, and that basal sliding does not occur.

\section{REFERENCES}

Chapuis, R. P. (1992). Similarity of internal stability criteria for granular soils. Can. Geotech. J. 29, No. 4, 711-713.

Domènech, G., Fan, X., Scaringi, G., van Asch, T. W., Xu, Q., Huang, R. \& Hales, T. C. (2019). Modelling the role of material depletion, grain coarsening and revegetation in debris flow occurrences after the 2008 Wenchuan earthquake. Engng Geol. 250, $34-44$.

Fan, X., Juang, C. H., Wasowski, J., Huang, R., Xu, Q., Scaringi, G., van Westen, C. J. \& Havenith, H. B. (2018). 
What we have learned from the 2008 Wenchuan earthquake and its aftermath: a decade of research and challenges. Engng Geol. 241, 25-32.

Fan, X., Scaringi, G., Korup, O., West, A. J., van Westen, C. J., Tanyas, H., Hovius, N., Hales, T. C., Jibson, R. W., Allstadt, K. E., Zhang, L., Evans, S. G., Xu, C., Li, G., Pei, X., Xu, Q. \& Huang, R. (2019). Earthquake-induced chains of geologic hazards: patterns, mechanisms, and impacts. Rev. Geophys. 57, No. 2, 421-503, https://doi.org/10.1029/ 2018RG000626.

Hu, W., Scaringi, G., Xu, Q., Pei, Z., Van Asch, T. W. \& Hicher, P. Y. (2017). Sensitivity of the initiation and runout of flowslides in loose granular deposits to the content of small particles: ann insight from flume tests. Engng Geol. 231, 34-44.

Hu, W., Hicher, P. Y., Scaringi, G., Xu, Q., Van Asch, T. W. J. \& Wang, G. (2018a). Seismic precursor to instability induced by internal erosion in loose granular slopes. Géotechnique $\mathbf{6 8}$, No. 11, 989-1001, https://doi.org/10.1680/jgeot.17.P.079.

Hu, W., Scaringi, G., Xu, Q. \& Huang, R. (2018b). Internal erosion controls failure and runout of loose granular deposits: evidence from flume tests and implications for postseismic slope healing. Geophys. Res. Lett. 45, No. 11, 5518-5527.

Hu, W., Scaringi, G., Xu, Q. \& Huang, R. (2018c). Acoustic emissions and microseismicity in granular slopes prior to failure and flow-like motion: the potential for early warning. Geophys. Res. Lett. 45, No. 19, 10-406.
Kenney, T. \& Lau, D. (1985). Internal stability of granular filters. Can. Geotech. J. 22, No. 2, 215-225.

Kenney, T. \& Lau, D. (1986). Internal stability of granular filters. Can. Geotech. J. 23, No. 3, 420-423, https://doi.org/10.1139/ t86-068.

Kezdi, A. (1979). Soil physics: selected topics, p. 160. Amsterdam, the Netherlands: Elsevier Scientific Publishing Co.

Li, M. \& Fannin, R. J. (2008). Comparison of two criteria for internal stability of granular soil. Can. Geotech. J. 45, No. 9, 1303-1309, https://doi.org/10.1139/t08-046.

Li, G., West, A. J., Densmore, A. L., Hammond, D. E., Jin, Z., Zhang, F., Wang, J. \& Hilton, R. G. (2016). Connectivity of earthquake-triggered landslides with the fluvial network: implications for landslide sediment transport after the 2008 Wenchuan earthquake. J. Geophys. Res.: Earth Surf. 121, No. 4, 703-724.

Sherard, J. L. (1979). Sinkholes in dams of coarse, broadly graded soils. Transactions of the 13th international congress on large dams, New Delhi, India, vol. 2, pp. 25-35.

Wang, W., Godard, V., Liu-Zeng, J., Scherler, D., Xu, C., Zhang, J., Xie, K., Bellier, O., Ansberque, C. \& de Sigoyer, J. \& ASTER Team (2017). Perturbation of fluvial sediment fluxes following the 2008 Wenchuan earthquake. Earth Surf. Process. Landf. 42, No. 15, 2611-2622.

Zhang, S., Zhang, L. M. \& Chen, H. X. (2014). Relationships among three repeated large-scale debris flows at Pubugou Ravine in the Wenchuan earthquake zone. Can. Geotech. J. 51, No. 9, 951-965. 